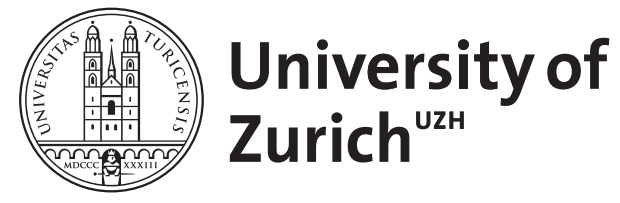

Zurich Open Repository and Archive

University of Zurich

University Library

Strickhofstrasse 39

CH-8057 Zurich

www.zora.uzh.ch

Year: 2014

\title{
The effect of individual differences in the development of metacognitive
} strategy knowledge

\author{
Karlen, Yves ; Maag Merki, Katharina ; Ramseier, Erich
}

DOI: https://doi.org/10.1007/s11251-014-9314-9

Posted at the Zurich Open Repository and Archive, University of Zurich ZORA URL: https://doi.org/10.5167/uzh-97963

Journal Article

Published Version

Originally published at:

Karlen, Yves; Maag Merki, Katharina; Ramseier, Erich (2014). The effect of individual differences in the development of metacognitive strategy knowledge. Instructional Science, 42(5):777-794.

DOI: https://doi.org/10.1007/s11251-014-9314-9 


\title{
The effect of individual differences in the development of metacognitive strategy knowledge
}

\author{
Yves Karlen • Katharina Maag Merki • Erich Ramseier
}

Received: 2 May 2013/Accepted: 12 March 2014/Published online: 28 March 2014

(C) Springer Science+Business Media Dordrecht 2014

\begin{abstract}
The aim of this study was to investigate the development of metacognitive strategy knowledge (MSK) during schooling at the upper secondary education level and to examine its relation with individual student characteristics. This longitudinal study with two measurement points analyzed a sample of students in grades 10 and 11 from 19 schools preparing students for university in Switzerland. The findings showed no development of MSK within a single year of school. Individual differences appeared in the level and the change of MSK over time. Female students as well as students with higher SES displayed higher MSK than male students and students with lower SES at the first measurement point. Furthermore, SES predicted changes in MSK over time. Between learning motivation and MSK as well as self-efficacy and MSK, high correlations were found at t1. Neither learning motivation nor self-efficacy had an effect on the change of MSK over time. The results show that there is still substantial potential for MSK development at the upper secondary education level. Implications for education and further studies are discussed.
\end{abstract}

Keywords Metacognition - Metacognitive strategy knowledge $\cdot$ Latent change analysis $\cdot$ Motivation $\cdot$ Self-regulated learning

\section{Introduction}

Metacognition is a complex, multifaceted construct and involves different terms and concepts (i.e., metacognitive beliefs, metacognitive skills, and metacognitive experiences) (e.g., Efklides 2008, 2011; Zohar 2012). It can be defined as awareness of one's own thinking and learning (Flavell 1979; Pintrich 2002; Schraw et al. 2006). Metacognition can

\footnotetext{
Y. Karlen $(\bowtie) \cdot$ K. M. Merki

Institute of Education, University of Zurich, Freiestrasse 36, 8032 Zurich, Switzerland e-mail: ykarlen@ife.uzh.ch

E. Ramseier

University of Teacher Education PHBern, Bern, Switzerland
} 
broadly be divided into two constituent parts: the knowledge component of metacognition consists, in the general understanding, of how learning occurs and how it can be improved through the application of different learning strategies. It is verbalizable knowledge about learning, understanding, and remembering processes and the conditions required for their development (Kuhn and Dean 2004). The regulation and monitoring component of metacognition serves to supervise, guide, and regulate the learning process and includes activities of planning, monitoring, and evaluating as well as awareness of comprehension and task performance (Schraw et al. 2006). According to Pressley et al. (1989), strategic action becomes possible through a complex interplay of metacognition, strategy use, and motivation. In this context, learners must direct their learning towards specific learning objectives, select appropriate learning strategies, monitor and regulate their learning processes, and maintain a high level of motivation (see also Borkowski et al. 2000). The important role of metacognition in the emergence and development of learning processes arises from its direct relationship to the different ways students learn, approach new learning situations and problems, and choose appropriate learning strategies (e.g., Veenman et al. 2006). Correspondingly, metacognition has been linked to higher achievement (e.g., Artelt and Neuenhaus 2010; Zohar and Peled 2008). This study focuses on the knowledge component of metacognition and describes the development of metacognitive strategy knowledge (MSK). There is some agreement in the literature that the development of MSK does not stop at the lower secondary school level but continues to develop in adulthood (Baker 2005; Brown et al. 1983; Lockl and Schneider 2007; Schneider 2010). Up to now, there has been a dearth of research on the development of MSK. A few empirical studies indicate that external factors, such as learning experiences, instruction, and teaching might influence the development of MSK (e.g., Paris and Paris 2001; Zohar and Peled 2008). Moreover, there is some evidence that internal factors, such as socioeconomic status (SES), motivation, or gender, are also related to MSK (e.g., Artelt et al. 2012; Pappas et al. 2003). However, there is still no clear picture to what extent different, especially internal, factors influence the development of MSK.

\section{Definition of metacognitive strategy knowledge}

In the literature, many different conceptualizations of metacognitive knowledge and terms for MSK can be found. The concept of MSK used in this study is related to Flavell's (1979) concept of declarative metacognitive knowledge. Flavell (1979) divided declarative metacognitive knowledge into knowledge about the self and other learners (person dimension), knowledge about tasks (task dimension), and knowledge about strategies (strategy dimension). Based on this theory, MSK is related to both the strategy and the task dimension. According to Efklides (2011), these two dimensions are related to each other because the selection of strategies is associated to the task demands. With respect to the concept of MSK, Paris et al. (1983) used the term conditional metacognitive knowledge, comprising knowledge of when and why a given strategy might be effective. MSK addresses the "When" and "Why" components and is hence related to that understanding. Further, MSK refers to the concept of relational metacognitive knowledge proposed by Borkowski et al. (1988) that includes knowledge about the possible uses of learning strategies and the relative benefits of a specific strategy over another. Kuhn and Pearsall (1998) used the term metastrategic understanding, i.e., knowledge of the conditions for using learning strategies, which correspond to our understanding of MSK. Taken together, MSK is a subcomponent of declarative metacognitive knowledge and is understood as explicit, conscious, and factual knowledge about memory and learning strategies. MSK involves knowledge about the attributes of 
strategies as well as knowledge about the relationship between the demands of a task and the application of strategies in order to master this task.

\section{Development of metacognitive strategy knowledge}

The development of metacognition begins at a very early age. Studies have shown that young children already possess basic metacognitive abilities (Baker 2005; Lockl and Schneider 2007; Schneider and Lockl 2006). In contrast, complex MSK is mainly acquired at a relatively advanced stage of human development. Since this is a demanding form of knowledge, it appears to develop rather slowly and mainly if it can be applied in challenging learning situations (Schneider 2010). According to the metamemory model of Borkowski et al. (2000), the development of MSK begins with the acquisition of domain-specific knowledge as children master specific learning strategies and discover the ways in which they are appropriate and effective. In the beginning, this knowledge is highly task-oriented and domainspecific (Neuenhaus et al. 2010). As learners acquire more learning strategies and learning experiences, they develop more flexible metacognitive strategy knowledge (Borkowski and Turner 1990). Having acquired knowledge about the relative benefits of one specific strategy over another, learners are able to select the appropriate learning strategies for a given task (Borkowski et al. 2000). Empirical evidence indicates developmental trends for MSK within 16 months for high school students (Artelt et al. 2012). However, even in adulthood, it still may not be fully developed, and deficits may exist (Brown et al. 1983).

The degree to which MSK is applied and develops depends inter alia on external factors: by offering systematic and structured learning experiences, school provides children with rich learning opportunities and thus the chance to develop MSK (e.g., Schraw et al. 2006). A significant developmental process can be identified over the course of the school years and with increasing years of school attendance (e.g., Schlagmüller and Schneider 2007). Maag Merki et al. (2013) found a significantly higher mean of MSK in a sample of university students than in a sample of students at the upper secondary education level. This result indicates that the development of MSK is related to learning experiences and years of school attendance. Different level of schooling offers different learning experiences; nevertheless, Lingel et al. (2010) found differences regarding school level with respect to the development of MSK. Students from a higher school level showed higher MSK than students from a lower school level (see also Artelt et al. 2009). Therefore, it can be assumed that the learning environment plays an important role in the context of fostering the development MSK. Zohar and Peled (2008) indicated that the explicit teaching of MSK supports the development of MSK.

Furthermore, a number of studies have identified individual student characteristics that influence the level and/or the development of MSK. For example, (Artelt et al. 2009) found gender differences, with girls showing higher levels of domain-specific MSK in the context of text comprehension than boys at the lower secondary education level. Also at the upper secondary education level girls showed higher metacognitive knowledge in the context of tackling larger essays or projects at school than boys (Maag Merki et al. 2013). One possible explanation for these gender differences might be that female students show higher effort and persistence in learning at school and use more complex learning strategies (e.g., Artelt et al. 2001a; Wolters 1999). Further, it has been observed that female students show better language skills and higher language related self-efficacy than male students (Huang 2012; OECD 2010). Research has shown that MSK develops with increasing age and age-related memory development (Roeschl-Heils et al. 2003; Schneider and Lockl 2002). In this context Pappas et al. (2003) have found that differences in SES might 
influence the development of metacognition already during the years of early childhood. Further, Artelt et al. (2001a) reported that, still at the lower secondary education level, a connection between a student's SES and MSK exists. Also Yerdelen-Damar and Pesman (2013) showed that high school students with higher SES had higher MSK. Alexander et al. (1995) found that the development of MSK is related to giftedness, showing higher development for children with higher intelligence (see also Alexander et al. 2003).

Besides these individual student characteristics, only few studies have focused on the relationship between MSK and motivation (Sperling et al. 2004). According to Schraw et al. 2006 p. 112), in the context of metacognition, learning motivation includes "beliefs and attitudes that affect the use and development of cognitive and metacognitive skills". Hence, learning motivation refers to an attribute that brings a person to engage or not to engage in strategic learning behavior. Theoretical models suggest a reciprocal relationship between learning motivation and MSK (Borkowski et al. 2000). On the one hand, Paris and Winograd (1990) mentioned that MSK enables students to be successful, which, in turn, has a positive effect on the students' learning motivation. On the other hand, higher levels of motivation encourage students to use MSK and empower students to be persistent and show engagement in their learning processes (Lai 2011). Such students experience more learning experiences, which might improve the development of MSK. Thillmann (2007) found that students used their MSK for a specific task mainly if they are motivated to engage in this task. Accordingly, considerable empirical evidence indicates a positive moderate association between MSK and different motivation variables (Bartels and Magung-Jackson 2009; Pierce and Lange 2000; Roeschl-Heils et al. 2003; Sperling et al. 2004). Artelt et al. (2003) also demonstrated a positive correlation between motivation and SES.

Efklides (2011) stated that self-efficacy and MSK are connected to each other (see also Schraw 1998). From a theoretical perspective, it is assumed that students who believe in their capacity set higher goals, show greater strategy flexibility, achieve higher performance, and are more likely to be metacognitively engaged (Bandura 1997; Caprara et al. 2008). In an empirical study with university students, Coutinho and Neuman (2008) showed that self-efficacy predicted metacognitive skills. Self-efficacious students had higher metacognition. In addition, self-efficacy has been shown to affect students' effort and persistence to take on challenging learning processes (Linnenbrick and Pintrich 2003). Further, self-efficacy is a positive predictor of deep processing, higher use of complex strategies, and higher performance (e.g., Pintrich and DeGroot 1990). Alexander et al. (2003) highlighted that self-efficacy is also positively correlated with SES (see also Yerdelen-Damar and Pesman 2013). SES showed high predictive validity for achievement and successful school careers in several international studies such as TIMSS and PISA (e.g., Artelt et al. 2001a; Kirsch et al. 2002; OECD 2007, 2010).

Taken together, these findings indicate that, besides external factors, internal factors play an important role in the development of MSK. However, results mainly stem from crosssectional or short-term studies. Empirical research systematically addressing the development of MSK is still rare. In this study, we examine the development of MSK based on an analysis of longitudinal data taking several individual characteristics into consideration (gender, SES, self-efficacy, and learning motivation), which, according to theoretical and empirical assumptions, may influence the development of MSK. Researchers have measured domain-specific MSK inter alia in the field of mathematics (Efklides and Vlachopoulus 2012; Artelt et al. 2012; Neuenhaus et al. 2010), first language (German) and second language (English) (Artelt et al. 2012) as well as reading (Schlagmüller and Schneider 2007). In this study, we apply a test to assess task-specific MSK for the handling of larger and complex essays or assignments (see Maag Merki et al. 2013). 


\section{Research questions and hypotheses}

This study deals with two research questions. The first of these is the question of whether students at the upper secondary education level demonstrate a development in task-specific MSK over the course of a single school year. Theoretical and empirical implications indicate that MSK develops through learning experiences (e.g., Schneider 2010). For example, results from a previous study showed that university students have higher MSK than students from the upper secondary school level (Maag Merki et al. 2013). Since all schools involved in this study participated in a school development project aiming to offer opportunities of self-regulated learning (SRL), we expected that they enable SRL experiences, which might foster MSK (see "Methods" section for more details). Yet, empirical studies investigating other education levels showed a development of MSK within a shorter term (e.g., Artelt et al. 2012; Lingel et al. 2010). Therefore, we hypothesized (A1) that the measured task-specific MSK also develops over the period of a 9-month term at Swiss schools preparing for university.

Second, we examined how individual student differences affect the level and development of MSK. Here, our hypotheses are the following: (B1) First, we hypothesized that female students show a higher initial level of MSK than male students (Artelt et al. 2009). (B2) Further, we hypothesized that gender is predictive for changes in MSK. In this respect, we expected female students to show a larger increase in MSK than male students. This is based on findings from previous studies indicating that female students spend more time studying, invest more effort, use more complex learning strategies more often, and have higher language skills than male students (e.g., OECD 2010; Wolters 1999), all of which can be expected to positively influence the development of MSK.

In line with empirical results showing that SES and MSK are positively related to each other (Artelt et al. 2001a; Pappas et al. 2003; Yerdelen-Damar and Pesman 2013), we hypothesized (B3) that students with higher SES show higher levels of MSK than students with lower SES. Moreover, according to this assumption, (B4) we expected that the SES predicts growth in MSK.

Based on theoretical assumptions and empirical results from previous studies (Bartels and Magung-Jackson 2009; Borkowski et al. 2000; Coutinho and Neuman 2008; Efklides 2011), we hypothesized (B5) that learning motivation as well as self-efficacy are positively related to MSK. Students with higher learning motivation and/or higher self-efficacy show higher engagement and persistence in learning and deeper learning approaches (e.g., Paris and Winograd 1990; Pintrich and DeGroot 1990). Therefore, (B6) we hypothesized positive effects for changes in MSK: students with higher learning motivation and/or higher self-efficacy may show a more positive development in MSK than less motivated or self-efficacious students.

\section{Methods}

Participants and context

A representative cohort of students in grades 10 and 11 from 19 state upper secondary education schools (ISCED Level 3A) in the Swiss canton of Zurich was assessed at the beginning (t1) and at the end ( 2 2) of the 2010/11 school year. The schools involved in this study prepare students for university over a period of 3-4 years. The interval between the two measurement points was 9 months. The online survey was administered in 73 classes 
during two regular school lessons, and teachers supervised the survey and ensured classroom discipline. In total, 2,433 evaluable questionnaires were received, corresponding to a response rate of $93 \%$ at $\mathrm{t} 1$ and of $86 \%$ at $\mathrm{t} 2$. Two classes participated at only one of the two measurement points and were therefore excluded. The final sample contained 1,272 students at $\mathrm{t} 1$ and 1,126 at t2. For 897 students, information at both measurement points is combined. Otherwise, information is only present at one point of time or cannot be linked because of missing individual matching. $58.6 \%$ were female and $41.4 \%$ male students, which all together had a mean age of $M=16.6$ years $(\mathrm{SD}=1.06)$.

In the context of a common school development project, the fostering of SRL skills was a common goal for all schools included. Regarding the conception, length, and content of the lessons, the schools received suggestions and support but no compulsive instruction from the educational authorities. Therefore, all schools created individual varieties of implementations and highly heterogeneous lessons.

Measures

\section{Metacognitive strategy knowledge}

Based on existing instruments for the assessment of MSK for other domains and tasks in other education levels (Artelt et al. 2009; Neuenhaus et al. 2010; Schlagmüller and Schneider 2007), we developed a new test instrument for the upper secondary education level (see Maag Merki et al. 2013 for details). The ability to autonomously handle a project and to write a report or essay is seen as an important competence at this level. Therefore, at the end of this education level, students must complete such a complex assignment and write a larger essay. Accordingly, the newly developed MSK test includes seven taskspecific learning scenarios, for which students were required to tackle a complex and larger assignment at school (see Appendix). The MSK test instrument takes the procedural structure of SRL into account (e.g., Schmitz 2001). The students were asked to rate the predetermined learning strategies (A-F in the example task, Table 1) according to their usefulness considering the requirements of the learning scenario at hand on a six-point scale ranging from 1 (not useful) to 6 (very useful).

The basis for calculating the MSK score was not the student's absolute rating of the individual learning strategy but the student's relative estimation of the usefulness of one learning strategy compared to another (pairs of strategies). The functionality ("correctness") of these estimations was assessed by their concordance with an expert appraisal (see Maag Merki et al. 2013 for more details). For that purpose, we asked researchers on teaching and learning from Germany and Switzerland as well as qualified teachers to fill out the same MSK test $(N=25)$. Only those 58 pair of strategies, which were rated equally by at least $75 \%$ of the experts were used for the calculation of the MSK score. Students were given one point for each pair of strategies that correspond with the experts" rating and zero for each pair rated that was inconsistently with the experts ' rating. For each scenario, we calculated a subscore based on the overall mean of all pairs considered in the given scenario. Finally, we used the average of all seven subscores to form the MSK score. The values of the MSK score vary between 0 (students have weak MSK, $0 \%$ correspondence with the experts) and 1 (students have high MSK $100 \%$ correspondence with the experts). The MSK test was administered identically at $\mathrm{t} 1$ and $\mathrm{t} 2$. Cronbach $\alpha$ of the test was .77 at $\mathrm{t} 1$ and .81 at $\mathrm{t} 2$. 
Table 1 Example task from the metacognitive strategy knowledge test

\begin{tabular}{l} 
How useful do you consider following strategies when you have difficulties in $\begin{array}{l}1=\text { Not useful } \\
\text { finding a topic for a complex assignment? }\end{array}$ \\
\cline { 2 - 4 } \\
\cline { 2 - 2 }
\end{tabular}

$\begin{array}{ll}\text { A } & \text { I think about which areas I am interested in } \\ \text { B } & \text { I wait for my teacher to suggest a topic } \\ \text { C } & \text { I discuss possible report topics with others (e.g., parents, friends) } \\ \text { D } & \text { I wait until a topic eventually comes to my mind } \\ \text { E } & \text { I go to the library and browse through books } \\ \text { F } & \text { I consider different topics and assess which ones are most practical }\end{array}$

\section{Number of books at home (SES)}

The question used to assess the socio-economic status referred to the number of books at home ("How many books do you have at home?") and ranged from 1 (0-10 books) to 6 (more than 500 books). It serves as rough but efficient indicator for SES emphasizing the cultural capital, particularly family educational background, home learning environment, as well as literacy and educational resources (e.g., Beaton et al. 1996; OECD 2007). As (Hansen and Munk 2012) showed, using data from the Progress in Reading Literacy Study (PIRLS), the number of books is the most important single indicator among several SES indicators. The number of books has also shown high predictive validity for achievement and successful school careers in several studies, e.g. TIMSS and PISA (Artelt et al. 2001a; Beaton et al. 1996; Kirsch et al. 2002).

\section{Learning motivation}

Learning motivation is a multifaceted construct including aspects of goal setting and volition. To assess learning motivation, we included three different scales: Intrinsic motivation was assessed by four items (Cronbach's $\alpha=.88$ ) (e.g., "I study because I am very interested in different facets of this subject."). Extrinsic motivation (success orientation) was assessed by six items (Cronbach's $\alpha=.84$ ) (e.g., "I study because I want to perform well"). Success orientation refers to the valuing of success and achievement in school. This extrinsic motivation scale is measuring either identified or integrated regulation-types of regulation contrary to introjected or external regulation with less favorable consequences for learning (Deci and Ryan 2002). Both intrinsic and extrinsic motivation refers to reasons why students spend time studying (Schiefele and Wild 2000). Complementarily, persistence refers to the capacity to stay on track with a task even if difficulties arise. In reference to Heckhausen's scale (1989), persistence was assessed by six items (Cronbach's $\alpha=.81$ ) (e.g., "Even with difficult assignments, I don't give up until I am finished"). This learning motivation can be seen as an indicator of a favorable motivational state.

\section{Self-efficacy}

To assess self-efficacy, a scale adapted from Jerusalem and Satow (1999) with four items (e.g., "When I try hard, I am able to solve even difficult tasks in class") ranging from 1 (not true at all) to 4 (very true) was used. The internal consistency was high, with a 
Cronbach's $\alpha$ of .84. Self-efficacy refers to a person's confidence to attain a specific outcome and overcome difficulties. This involves beliefs and perceptions about the self, which are related to past learning experiences and achievement. Self-efficacy plays an important role in a person's future development, action, and SLR skills (Bandura 1997; Caprara et al. 2008).

The items used to measure learning motivation and self-efficacy were framed specifically for the academic subject of German (first language) because the topics dealt within the MSK test correspond most closely to the demands in this academic subject. In Swiss schools that prepare students for university, not only correct spelling, writing style, etc. are important, but even more the competence to write essays. Further, an overlap between learning motivation, self-efficacy and SES can be expected.

Statistical analyses

In a first step, a confirmatory factor analysis (CFA) of the scenario subscales assessing MSK was conducted to evaluate whether there was an adequate fit between the theoretical model and the empirical data. Further, CFA was used to determine the level of measurement invariance between the two measurement points (see Brown 2006; Moosbrugger and Schermelleh-Engel 2006).

In a second step, latent change $(L C)$ models were conducted to estimate the development of MSK. LC models offer a direct approach to investigate change over time and can be understood as specific structural equation models that depict the difference in mean values between two measurement points by a true (corrected for measurement errors) LC factor. This factor is calculated as the difference between $\mathrm{t} 1$ and $\mathrm{t} 2$ and represents the growth or decline from one measurement point to another (i.e., variable LC_MSK in Fig. 1). The latent factor for $\mathrm{t} 2$ is decomposed into the factor at $\mathrm{t} 1$ and the $\mathrm{LC}$ factor (see Fig. 1). LC factors can be treated as independent or dependent variables in a structure equation model (Geiser et al. 2010; Steyer et al. 1997).

Finally, the association between MSK, gender, SES, learning motivation, and selfefficacy was analyzed based on a structural equation model (SEM). The LC variable of MSK was integrated in this model as dependent variable.

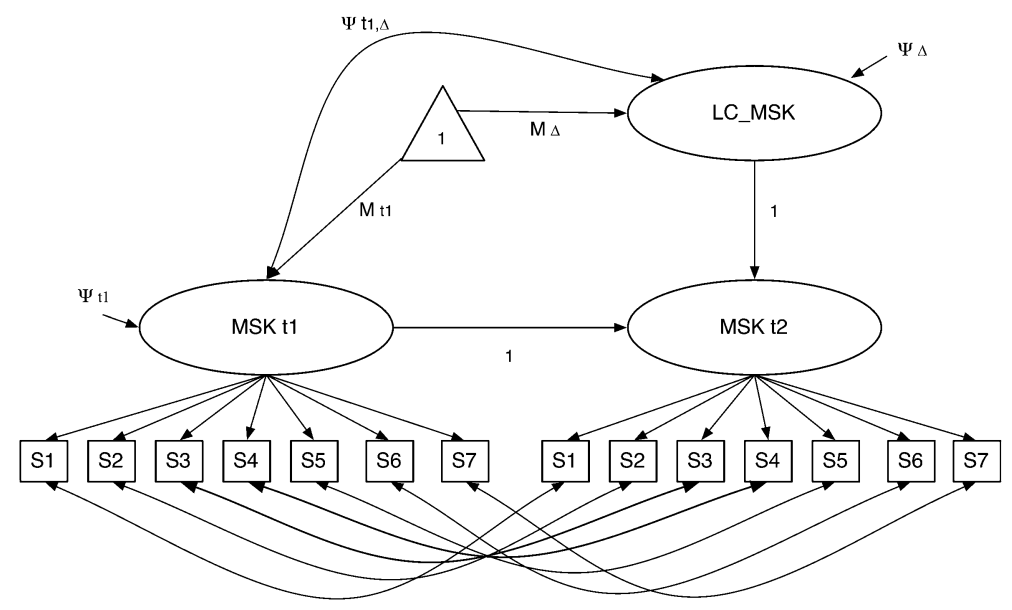

Fig. 1 Latent change model of metacognitive strategy knowledge 
To evaluate the models' fit, we examined the following goodness-of-fit indices more closely: the $\chi^{2}$ value relative to the degrees of freedom, the comparative fit index (CFI), and the root mean square error of approximation (RMSEA). These goodness-of-fit indices, in line with those reported by Schermelleh-Engel et al. (2003), are particularly suitable for determining the model fit. Further, the Bayesian Information Criterion (BIC) was used for model comparison (Geiser et al. 2010). A lower BIC value indicates a better fit of the model with the data. The full information maximum likelihood (FIML) method available in Mplus 6.0 (Muthén and Muthén 2010) was used in all analyses to consider cases with missing values. Across all cells of the covariance matrix analyzed, $94 \%$ of the values were valid on average and $92 \%$ at a minimum. The multilevel structure of the sample of students within classes was taken into account, making it possible to prevent misjudgment of the standard errors.

\section{Results}

Goodness-of-fit of the latent change models

Measurement invariance over time should be tested while analyzing the true change in longitudinal studies (Geiser et al. 2010). Using CFA and the $\Delta \chi^{2}$ test, the condition of strong measurement invariance - that is, the consistency in factor loadings and intercepts over time-was tested by comparing the baseline model (loadings freely estimated) with the constrained model. The $\Delta \chi^{2}$ test $\left(\Delta \chi^{2}=66.383 ; d f=21 ; p<.001\right)$ revealed that the fit of the constrained model was significantly different from the fit of the baseline model. Referring to Byrne et al. (1989); Geiser et al. (2010) demonstrated that partial measurement invariance can be sufficient for the interpretation of the differences in latent means over time. The $\Delta \chi^{2}$ test $\left(\Delta \chi^{2}=28.856 ; d f=20 ; p=0.091\right)$ revealed that the fit of the model with partial measurement invariance (intercepts of the scenario subscale 4 are not time-invariant) was not significantly different from the fit of the baseline model. This model yielded a good fit $\left(\chi^{2}=225.575\right.$, $\mathrm{df}=80$; CFI $=.97$; RMSEA $\left.=.036\right)$. Further, this model showed a lower BIC value $(3,862)$ than the baseline model (BIC value $=3,913)$. These results indicate that the assumption of partial measurement invariance is tenable. However, sensitivity analyses showed no changes of the coefficient between both models.

Modification indices for the LC model indicate that correlations between subscales (scenarios) 1 and 2 and subscales 6 and 7 should be allowed. The subscales 1 and 2 contain mainly organization and planning strategies and refer to the pre-action phase of an SRL process model (see Maag Merki et al. 2013). The subscales 6 and 7 refer to the learning scenarios 6 and 7 (see Appendix), in which mainly monitoring and evaluation strategies are listed. Both dimensions refer to the regulation components of metacognition (Schraw et al. 2006). This small modification led to a corresponding improvement in the fit of the LC model $\left(\chi^{2}=161.582, d f=78 ; \mathrm{CFI}=.98 ; \mathrm{RMSEA}=0.027\right)$. This model showed a lower BIC value $(3,813)$ than the model without the correlation (BIC value $=3,862$ ), indicating that this model fit best with the data. Table 2 shows the standardized estimated intercepts, latent factor loadings, and variance components for the LC model. Each single manifest indicator shows high reliability. The loadings for the latent factors (range $=.49-$ .77) are satisfying, which indicates that the latent factors are homogeneous. Further, the factor reliability values are high for all included scenarios (range $=.68-.86$ ). 
Table 2 Standardized estimated intercepts, factor loadings, and variance components in the latent change model

\begin{tabular}{|c|c|c|c|c|c|}
\hline Variable & Intercepts & Estimate (S.E.) & Factor loadings & Factor reliabilities & Covariance coverage \\
\hline \multicolumn{6}{|l|}{ Time 1} \\
\hline Scenario1 & $0.00+$ & 0.00 & $.60 * * *$ & .78 & .86 \\
\hline Scenario2 & $-.23 *$ & .11 & $.68 * * *$ & .82 & .85 \\
\hline Scenario3 & .11 & .10 & $.49 * * *$ & .80 & .84 \\
\hline Scenario4 & .08 & .09 & $.46^{* * * *}$ & .68 & .85 \\
\hline Scenario5 & $-.43 * * *$ & .11 & $.71 * * *$ & .82 & .86 \\
\hline Scenario6 & $-.43 * * *$ & .11 & $.51 * * *$ & .84 & .85 \\
\hline Scenario7 & $-.40 * * *$ & .10 & $.55^{* * *}$ & .86 & .85 \\
\hline \multicolumn{6}{|l|}{ Time 2} \\
\hline Scenario1 & $0.00+$ & 0.00 & $.66 * * *$ & .80 & .72 \\
\hline Scenario2 & $-.22 *$ & .10 & $.63 * * *$ & .86 & .72 \\
\hline Scenario3 & .10 & .10 & $.53 * * *$ & .80 & .71 \\
\hline Scenario4 & $.08 * * *$ & .09 & $.53 * * *$ & .68 & .72 \\
\hline Scenario5 & $-.41 * * *$ & .11 & $.77 * * *$ & .85 & .72 \\
\hline Scenario6 & $-.40 * * *$ & .10 & $.65 * * *$ & .84 & .72 \\
\hline Scenario7 & $-.38 * * *$ & .09 & $.59 * * *$ & .88 & .72 \\
\hline
\end{tabular}

Notes: Fixed parameters are marked with a plus sign $(+), * * * p<.001 ; * p<.05$

Differences in level and change of metacognitive strategy knowledge

The first question addresses whether upper secondary education school students' MSK increases within a period of 9 months. The results revealed no increase in MSK within a single school year. The LC variable of MSK showed a small true (corrected for measurement error) nonsignificant mean $(\mathrm{M}=.002)$. At both measurement points, the latent MSK score was $\mathrm{M}=.64$.

To address our second question regarding interindividual differences in level and intraindividual changes in MSK, we estimated an SEM. First, we analyzed the fit of the SEM with the data (see Fig. 2). The model immediately showed adequate fit indices: $\chi^{2}=365,716 ; d f=161 ; \mathrm{CFI}=.97 ; \mathrm{RMSEA}=.029$.

Gender was highly predictive of the MSK level $(\beta=.32 ; p<.001)$. Female students outperformed male students in terms of their level of MSK at t1. Gender did not, however, predict changes in MSK. The results showed a small direct significant effect $(\beta=.09$; $p<.05)$ of SES on MSK at 1 . Furthermore, SES was predictive of changes in MSK. Nevertheless, the effect was small with $\beta=.09(p<.05)$. Self-efficacy was significantly correlated $(r=.19 ; p<.001)$ with MSK at t1. The higher students' individual self-efficacy, the higher their MSK. The results showed no effect of self-efficacy on changes in MSK. Learning motivation and MSK were also associated with each other. A positive correlation of $r=.29$ ( $p<.001)$ was found between learning motivation and MSK at $\mathrm{t}$. Thus, students who reported a higher level of learning motivation also showed a higher level of MSK. However, learning motivation did not predict changes in MSK. Overall, no indirect effects on changes in MSK were found. Gender and SES displayed significant 


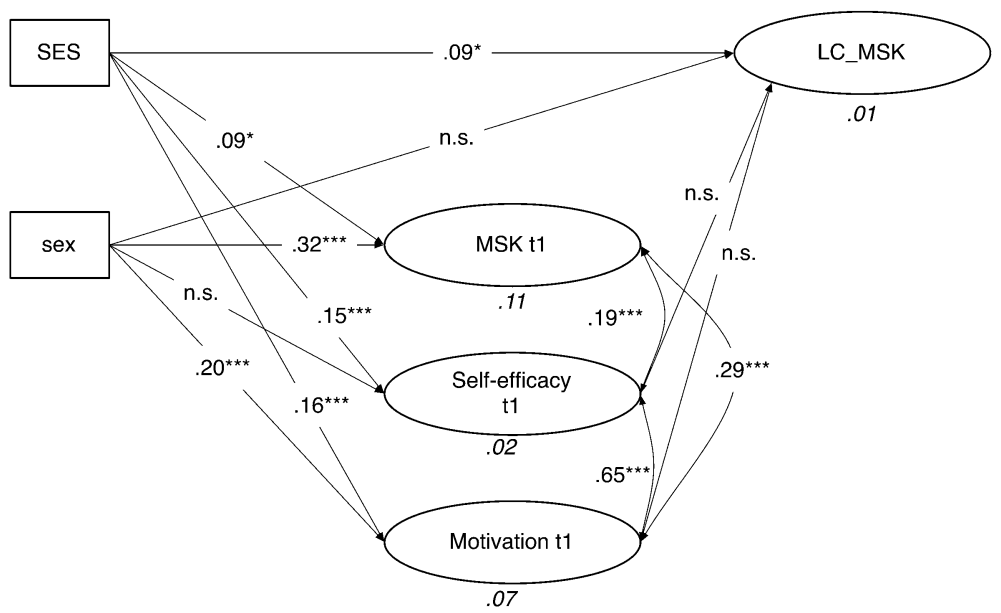

Fig. 2 Structural equation model with standardized path coefficients and the proportions of explained variance (italics). $* * * p<.001 ; * p<.05$

effects on learning motivation $(\beta=.20 / \beta=.16 ; p<.001)$. Females and students with a higher SES had higher starting scores for learning motivation than males and students with a lower SES. Furthermore, SES had a positive effect of $\beta=.15(p<.001)$ on selfefficacy. In contrast, no significant effect of gender on self-efficacy was found. The model explained $11 \%$ of the variance in MSK at $\mathrm{t} 1$. For learning motivation, $7 \%$ of the variance was explained at $\mathrm{t} 1$, and for self-efficacy it was $3 \%$. For the LC MSK variable, the explained variance was very small $(1 \%)$.

In sum, the results show no increase of MSK within a period of 9 months in schools at the upper secondary education level preparing for university. Furthermore, nearly no influence of individual characteristics on the development of MSK was found. Only SES revealed a small effect on changes in MSK. However, individual differences could be observed in the level of MSK. Female students as well as students with a higher SES displayed a higher level of MSK than male students and students with a low SES. Furthermore, significant correlations between learning motivation and MSK as well as between self-efficacy and MSK were found.

\section{Discussion}

The aim of this study was to investigate individual differences in the level and the development of MSK over the course of a single school year. To assess MSK, we used a standardized instrument for measuring task-specific MSK in the completion of complex and larger assessments (Maag Merki et al. 2013). The results show no increase in but stability of task-specific MSK within a single school year. On this basis, we reject our first hypothesis A1. This result contrasts partially with previous findings from other studies reporting a development of MSK at lower secondary education level (e.g., Artelt et al. 2012). According to Schneider (2010), MSK is a complex form of knowledge, which develops slowly over time and only in the context of systematic learning experiences. In this respect, it might be possible that students have not made enough context-related learning experiences to develop this type of MSK. Although the fostering of SRL 
experiences in class was a common goal of all schools included in this study, the instruction of strategy use and the thinking about learning might not have been explicit enough to foster MSK. Further, a major project that is related to the MSK test, the final larger essay, is typically written during the last year of schooling (grade 12). It can therefore be argued that the students tested in our study lacked the necessary experience to address the themes dealt within the test. Results from previous research support this assumption, showing that university students have a higher level of MSK than students from the upper secondary education level (Maag Merki et al. 2013). However, it might be that students developed other types of MSK.

When focusing on the influence of individual characteristics on the level of MSK at t1, several differences can be identified. Gender and SES were significantly predictive of the level of MSK at t1, confirming our hypotheses (B1, B3). These results are consistent with findings from previous studies, which reported gender differences favoring female students (e.g., Artelt et al. 2009). These results are also consistent with findings showing that a high SES is related to a higher level of MSK (e.g., Artelt et al. 2001b). In sum, the reported individual differences in the level of MSK found in lower education still retain to the upper education level. However, gender did not predict changes in MSK, leading us to reject hypothesis B2. This means that the lead of female students regarding the level of MSK does not result in a more positive development. However, neither do male students make up their inferior position regarding the level of MSK. In line with our hypothesis (B4), SES did predict changes in MSK. These results are in line with findings from studies on preschool children (Pappas et al. 2003) and lower secondary school students (Artelt et al. 2001a). The number of books was used as a rough indicator of SES. This indicator reflects literacy resources at home and school-friendly family background. Students with higher SES may have a more favorable learning environment than students with lower SES. Therefore, they might have additional opportunities to make meaningful learning experiences outside school. This assumption is in line with results from studies showing that students with high SES showed successful school careers and higher achievement in international studies such as the PISA and IEA Reading Literacy Study (e.g., Hansen and Munk 2012; Kirsch et al. 2002). Further, this indicator is also related to language skills (e.g., text comprehension and reading skills), which may partially explain the effect found in this study (e.g., Huang 2012; Kirsch et al. 2002). The MSK test used in this study is also related to language and reading skills as the MSK test refers to the specific situation of tackling a larger and complex assessment (i.e., essay). In this situation, language competency, the dealing with literature, and text comprehension are important skills for the successful handling of this kind of assessment.

In the SEM, we modeled correlations between learning motivation and MSK as well as self-efficacy and MSK based on theoretical and empirical assumptions (e.g., Borkowski and Turner 1990; Coutinho and Neuman 2008; Pressley et al. 1989). We found meaningful correlations between learning motivation, self-efficacy, and MSK, as predicted. This is in line with our hypothesis B5. Further, positive effects of learning motivation and selfefficacy on changes in MSK were expected. The results, nevertheless, showed no effects; therefore, our hypothesis B6 has to be rejected. Research showed that learning orientation predicts engagement in metacognitive activities (e.g., Sperling et al. 2004). The development of MSK, however, is mainly a product of complex and specific learning experiences as well as explicit reflection (De Corte et al. 2000). Therefore, a possible explanation may be that additional effort and persistence in learning were related to a surface understanding of factual knowledge and not to further effort in strategic learning and reflection of one's own learning processes. 
Although not the main focus of this study, our results on the effects modeled in the SEM also provide the basis for conclusions about individual differences in the level of learning motivation. The results show that gender is predictive of the level of learning motivation. Thus, female students show higher learning motivation in the academic subject of German than male students. This result is consistent with similar gender-specific findings from other studies for the same academic subject (e.g., OECD 2010). Gender shows no effect on language self-efficacy. This is partially surprising when considering the findings from Huang (2012), who found an overall positive correlation between language self-efficacy and female students in his meta-analysis. Our results demonstrate direct effects of SES on learning motivation and self-efficacy for the school subject German. This result is again in line with similar results from Artelt et al. (2003) who showed that SES is related to higher motivation and self-efficacy level in the context of reading competencies. Our results demonstrate direct effects of SES on learning motivation and self-efficacy for the school subject German. This result is again in line with similar results from Artelt et al. (2003) who showed that SES is related to higher motivation and self-efficacy level in the context of reading competencies.

As a limitation of this study, it should be noted that only a very small proportion of the variance in MSK could be explained. On the one hand, this suggests that further internal factors such as intelligence (Alexander et al. 2003), cognitive competencies (Lockl and Schneider 2007) as well as other motivational factors such as self-concept (Kleitman and Strankov 2007; Meneghetti and De Beni 2010) could be important. Furthermore, especially regarding the task-specific MSK test, language competencies should be considered. On the other hand, as mentioned in the theoretical literature, external factors (e.g., explicit teaching and learning environment) may play a crucial role in the development of MSK and should be analyzed as well. In this study, the interaction effect between internal and external factors was not analyzed. Therefore, further research should include a more sophisticated model considering particularly this interaction. As a consequence, the impact of internal factors on MSK and the change over time may decrease. Such analyses could help developing beneficial learning environments for the development of MSK.

Learning motivation and self-efficacy were framed for the academic subject of German and not for the specific tasks used in this MSK test, representing another weak point. The incomplete accordance between learning motivation as well as self-efficacy and the MSK test might have account for the nonsignificant effect found on the development of MSK. Therefore, it is suggested for further studies to provide a higher accordance between motivational variables and the measured MSK. Another limitation of this study is the measurement of SES. Our SES indicator, the number of books at home, is strongly limited with a focus on the family educational background. Nevertheless, it is a valid indicator for SES (Hansen and Munk 2012), and several empirical studies have shown that the number of books is a strong predictor of achievement in several domains (e.g., Kirsch et al. 2002; OECD 2010). In order to investigate the relationship between SES and MSK more thoroughly, further studies should use more differentiated measures of SES (e.g., parents' educational background, job level) and mediating variables should be included to enlighten the causal pathway between SES and MSK. Furthermore, there might be an overlap between the operationalization of SES and MSK since both are related to literacy resources. In samples with heterogeneous literacy skills, this overlap might influence the relation between both variables. However, our study only included students from highly demanding schools that prepare them for university entrance. Since high language skills are a prerequisite for these schools, we can exclude the risk that such a potential overlap would have biased our results. 
From a theoretical and research perspective, more dynamic models focusing on the development of MSK are needed, which include internal and external factors. Theoretical assumptions have to be clarified and integrated into a dynamic model that explains how they contribute to the development of MSK. Due to the fact that no increase in MSK development within a 9-month term could be found, further research may extend the twowave longitudinal design as well as the interval of time between the measurement points. In addition, more explicit and practicable concepts for the fostering of MSK in school lessons are needed. The potential for improving task-specific MSK at the upper secondary education level is still significant as there is a great difference between the mean MSK score of all students and the possible maximal MSK score. Further, intraindividual differences found between childhood and adolescence (e.g., gender differences) still exist in young adulthood. Even though schools received suggestions from the educational authorities to foster SRL skills, no development in MSK was found. Therefore, it might be important to pay more attention to the promoting of MSK in school. Students may need help to become strategic strategy users and successful self-regulated learners. This will become particularly significant as soon as students have to write their final essay or move to university. Further, it cannot be taken for sure that students become successful selfregulated learners on their own (Bjork et al. 2013). Therefore, teachers should provide specific feedback on learning and explain the advantages of strategic learning as well as highlight the significance of metacognition. Students may need explicit descriptions of learning strategies as well as information about when and how to use them in order to develop their MSK. Further, teachers should support and foster students to take responsibility for their own learning process, so that they may use their MSK (Paris and Paris 2001). Because of the gender differences observed in this study, male students should receive targeted support in this area. Moreover, schools should offer students with lower SES systematic opportunities to practice and use learning strategies and thus to further develop their MSK. One important precondition for the use of MSK in learning situations is a student's motivational state. If a person is not motivated to invest effort and time for learning, the person will not activate metacognitive procedures (Borkowski et al. 2000; Thillmann 2007; Rheinberg et al. 2005). Teachers should keep students motivated to engage in strategic learning behavior and foster students' self-efficacy. Furthermore, teacher should help students to experience success in strategic learning behavior in the context of tackling challenging task. This could increase students' learning motivation and selfefficacy related to the use of MSK (Paris and Winograd 1990).

\section{Appendix}

See Table 3

Table 3 Learning scenarios and example items of the metacognitive strategy knowledge test

\begin{tabular}{lll}
\hline Scenario & Subject area & Example item and pair* \\
\hline 1 (6 items, 7 pairs) & Having difficulties finding a topic & $\begin{array}{c}\text { A: I think about what topics I am interested } \\
\text { in } \\
\end{array}$ \\
B: I wait for my teacher to suggest a topic \\
\hline
\end{tabular}


Table 3 continued

\begin{tabular}{|c|c|c|}
\hline Scenario & Subject area & Example item and pair* \\
\hline 2 (7 items, 6 pairs) & Gaining an overview of the topic & $\begin{array}{l}\text { A: I ask myself what I already know about } \\
\text { the topic } \\
\text { B: I don't waste time on research; I prefer to } \\
\text { start writing }\end{array}$ \\
\hline 3 (8 items, 10 pairs) & Becoming familiar with the topic & $\begin{array}{l}\text { A: I read the tables of contents of books or } \\
\text { the titles of articles } \\
\text { B: I browse through a book and start writing }\end{array}$ \\
\hline 4 (6 items, 6 pairs) & $\begin{array}{l}\text { Establishing contact with the } \\
\text { teacher }\end{array}$ & $\begin{array}{l}\text { A: I only turn to my teacher for advice when } \\
\text { I have specific questions } \\
\text { B: I work by myself and try to overcome } \\
\text { difficulties as good as possible }\end{array}$ \\
\hline 5 (10 items, 12 pairs) & Having trouble solving difficulties & $\begin{array}{l}\text { A: I remind myself of the aims of my paper } \\
\text { and examine whether I am still on the right } \\
\text { track } \\
\text { B: I decide to shorten my essay }\end{array}$ \\
\hline 6 (8 items, 9 pairs) & Finishing off the task & $\begin{array}{l}\text { A: I first write a list with all issues I would } \\
\text { like to check (e.g., spelling) } \\
\text { B: I read the report one last time and correct } \\
\text { whatever I happen to notice }\end{array}$ \\
\hline 7 (7 items, 8 pairs) & $\begin{array}{l}\text { Drawing conclusions for similar } \\
\text { tasks in the future }\end{array}$ & $\begin{array}{l}\text { A: I will pay closer attention to the aims and } \\
\text { requirements of the assignment } \\
\text { B: I try to forget the poor evaluation }\end{array}$ \\
\hline
\end{tabular}

* Response categories: 1 (not at all useful) to 6 (very useful); Strategy A > Strategy B

\section{References}

Alexander, J. M., Carr, M., \& Schwanenflugel, P. J. (1995). Development of metacognition in gifted children: Directions for future research. Developmental Review, 15, 1-37.

Alexander, J. M., Fabricius, W. V., Fleming, V. M., Zwahr, M., \& Brown, S. A. (2003). The development of metacognitive causal explanations. Learning and Individual Differences, 13, 227-238.

Artelt, C., Baumert, J., Julius-McElvaney, N., \& Peschar, J. (2003). Learners for life. Students approaches to learning. Paris: OECD.

Artelt, C., Beinick, A., Schlagmüller, M., \& Schneider, W. (2009). Diagnose von Strategiewissen beim Textverstehen [Diagnosing strategy knowledge in text comprehension]. Zeitschrift für Entwicklungspsychologie und Pädagogische Psychologie, 41(2), 96-103.

Artelt, C., Demmrich, A., \& Baumert, J. (2001a). Selbstreguliertes Lernen [Self-regulated learning]. In J. Baumert, E. Klieme, M. Neubrand, M. Prenzel, U. Schiefele, W. Schneider, P. Stanat, K.-J. Tillmann, \& M. Weiss (Eds.), PISA 2000: Basiskompetenzen von Schülerinnen und Schülern im internationalen Vergleich [Students' basic competencies in international comparison] (pp. 271-298). Opladen: Leske + Budrich.

Artelt, C., \& Neuenhaus, N. (2010). Metacognition und Leistung. [Metacognition and Achievement] In W. Bos, E. Klieme, \& O. Köller (Eds.), Schulische Lerngelegenheiten und Kompetenzentwicklung. Festschrift für Jürgen Baumert [Learning opportunities in school and competency development. A commemorative publication for Jürgen Baumert] (pp. 127-146). Münster: Waxmann.

Artelt, C., Neuenhaus, N., Lingel, K., \& Schneider, W. (2012). Entwicklung und wechselseitige Effekte von metacognitiven und bereichsspezifischen Wissenskomponenten in der Sekundarstufe [Development and mutual effects of metacognitive and subject-specific knowledge components at the secondary school level]. Psychologische Rundschau, 63(1), 18-25.

Artelt, C., Schiefele, U., \& Schneider, W. (2001b). Predictors of reading literacy. European Journal of the Psychology of Education, 16(3), 363-383.

Baker, L. (2005). Developmental differences in metacognition: Implications for metacognitively oriented reading instruction. In S. E. Israel, K. L. Bauserman, K. Kinnucan-Welsch, \& C. C. Block (Eds.), 
Metacognition in literacy learning: Theory, assessment, instruction, and professional development (pp. 61-79). Mahwah: Lawrence Erlbaum.

Bandura, A. (1997). Self-efficacy: The exercise of control. New York: Freeman.

Bartels, J. M., \& Magung-Jackson, S. (2009). Approach-avoidance motivation and metacognitive selfregulation: The role of need for achievement and fear of failure. Learning and Individual Differences, 19, 459-463.

Beaton, A. E., Mullis, I. V. S., Martin, M. O., Gonzales, E. J., Kelly, D. L., \& Smith, T. A. (1996). Mathematics achievement in the middle school years: IEA's Third International Mathematics and Science Study (TIMSS). Chestnut Hill, MA: Boston College.

Bjork, R. A., Dunlosky, J., \& Kornell, N. (2013). Self-regulated learning: Beliefs, technique, and illusion. Annual Review of Psychology, 64, 417-444.

Borkowski, J. G., Chan, L. K. S., \& Muthukrishna, N. (2000). A process-oriented model of metacognition: Links between motivation and executive functioning. In G. Schraw \& J. C. Impara (Eds.), Issues in the measurement of metacognition (pp. 1-42). Lincoln: Buros Institute of Mental Measurements.

Borkowski, J. G., Milestead, M., \& Hale, C. (1988). Components of children's metamemory. In F. E. Weinert \& M. Perlmutter (Eds.), Memory development: universal changes and individual differences (pp. 73-100). Hillsdale: Lawrence Erlbaum.

Borkowski, J. G., \& Turner, L. A. (1990). Transsitutional characteristics of metacognition. In W. Schneider \& F. E. Weinert (Eds.), Interactions among aptitudes, strategies, and knowledge in cognitive performance (pp. 159-176). New York: Springer.

Brown, T. A. (2006). Confirmatory factor analysis for applied research. New York: Guilford Press.

Brown, A. L., Bransford, J. D., Ferrara, R. A., \& Campione, J. C. (1983). Learning, remembering and understanding. In P. H. Mussen (Ed.), Handbook of child psychology (Vol. 3, pp. 77-166). New York: Wiley.

Byrne, B. M., Shavelson, R. J., \& Muthén, B. (1989). Testing for the equivalence of factor covariance and mean structures: The issue of partial measurement invariance. Psychological Bulletin, 105, 456-466.

Caprara, G. V., Fida, R., Vecchione, M., Del Bove, G., Vecchio, G. M., Barbaranelli, C., et al. (2008). Longitudinal analysis of the role of perceived self-efficacy for self-regulated learning in academic continuance and achievement. Journal of Educational Psychology, 100(3), 525-534.

Coutinho, S. A., \& Neuman, G. (2008). A model of metacognition, achievement goal orientation, learning style and self-efficacy. Learning Environment Research, 11, 131-151.

De Corte, E., Verschaffel, L., \& Eynde, P. O. (2000). Self-regulation: A characteristic and a goal of mathematics education. In M. Boekaerts, P. R. Pintrich, \& M. Zeidner (Eds.), Handbook of selfregulation (pp. 687-726). San Diego: Academic Press.

Deci, E. L., \& Ryan, R. M. (2002). Handbook of self-determination research. Rochester, NY: University of Rochester Press.

Efklides, A. (2008). Metacognition. Defining its facets and levels of functioning in relation to self-regulation and co-regulation. European Psychologist, 13, 277-287.

Efklides, A. (2011). Interactions of metacognition with motivation and affect in self-regulated learning: The MASRL model. Educational Psychologist, 46(1), 6-25.

Efklides, A., \& Vlachopoulos, (2012). Measurement of metacognitive knowledge of self, task, and strategies in mathematics. European Journal of Psychological Assessment, 28(3), 227-239.

Flavell, J. H. (1979). Metacognition and cognitive monitoring. A new area of cognitive developmental inquiry. American Psychologist, 34, 906-911.

Geiser, C., Eid, M., Nussbeck, F. W., Courvoisier, D. S., \& Cole, D. A. (2010). Analyzing true change in longitudinal multitrait-multimethod studies: Application of a multimethod change model to depression and anxiety in children. Developmental Psychology, 46(1), 29-45.

Hansen, K. Y., \& Munk, I. (2012). Exploring the measurement profiles of socioeconomic background indicators and their differences in reading achievement: A two-level latent class analysis. IERI Monograph Series: Issues and Methodologies in Large-Scale Assessments, 5, 49-77.

Heckhausen, H. (1989). Motivation und Handeln [Motivation and action]. Berlin: Springer.

Huang, C. (2012). Gender differences in academic self-efficacy: a meta-analysis. European Journal of Psychology of Education, 28(1), 1-35. doi:10.1007/s10212-011-0097-y.

Jerusalem, M., \& Satow, L. (1999). Schulbezogene Selbstwirksamkeitserwartung [School related expectation of self-efficacy]. In R. Schwarzer \& M. Jerusalem (Eds.), Skalen zur Erfassung von Lehrer- und Schülermerkmalen: Dokumentation der psychometrischen Verfahren im Rahmen der Wissenschaftlichen Begleitung des Modellversuchs Selbstwirksame Schulen [Scales for measuring teacher and students characteristics: Documentation of psychometric procedures in the context of scientific accompaniment of the experiment of self-efficacy schools] (pp.15-16). Berlin: Freie Universität Berlin. 
Kirsch, I., de Jong, J., Lafontaine, D., McQueen, J., Mendelovits, J., \& Monseur, C. (2002). Reading for Change. Performance and Engagement across Countries. Results from PISA 2000. Paris: OECD.

Kleitman, S., \& Stankov, L. (2007). Self-confidence and metacognitive processes. Learning and Individual Differences, 17, 161-173.

Kuhn, D., \& Dean, D. (2004). A bridge between cognitive psychology and educational practice. Theory into Practice, 43(4), 268-273.

Kuhn, D., \& Pearsall, S. (1998). Relations between metastrategic knowledge and strategic performance. Cognitive Development, 13, 227-247.

Lai, E. R. (2011). Metacognition: A Literature Review. Research Report. London: Pearson. https://psychcorp. pearsonassessments.com/hai/images/tmrs/Metacognition_Literature_Review_Final.pdf. Accessed on 11 June 2013.

Lingel, K., Neuenhaus, N., Artelt, C., \& Schneider, W. (2010). Metacognitives Wissen in der Sekundarstufe: Konstruktion und Evaluation domänenspezifischer Messverfahren [Metacognitive knowledge at the secondary school level: Construction and evaluation of domain-specific measurement instruments]. In E. Klieme, D. Leutner \& M. Kenk (Eds.), Kompetenzmodellierung. Zwischenbilanz des DFGSchwerpunktprogramms und Perspektiven des Forschungsansatzes [Modeling competency: Interim report on the DFG Priority Program and perspectives of the research approach]. Zeitschrift für Pädagogik. 56. Beiheft (pp. 228-238). Weinheim: Beltz.

Linnenbrick, A., \& Pintrich, P. (2003). The role of self-efficacy beliefs in student engagement and learning in the classroom. Reading and Writing Quarterly, 19, 119-137.

Lockl, K., \& Schneider, W. (2007). Knowledge about the mind: Links between theory of mind and later metamemory. Child Development, 78(1), 148-167.

Maag Merki, K., Ramseier, E., \& Karlen, Y. (2013). Reliability and validity analyses of a newly developed test to assess learning strategy knowledge. Journal of Cognitive Education and Psychology, 12(3), 391-408.

Meneghetti, C., \& De Beni, R. (2010). Influence of motivational beliefs and strategies on recall task performance in elementary, middle and high school students. European Journal of Psychology of Education, 25(3), 325-343.

Moosbrugger, H., \& Schermelleh-Engel, K. (2006). Faktorenanalyse [factor analysis]. In F. Pertmann \& M. Eid (Eds.), Handbuch der Psychologischen Diagnostik [Handbook of psychological diagnostic] (pp. 304-317). Göttingen: Hogrefe.

Muthén, L. K., \& Muthén, B. O. (2010). Mplus user's guide (6th ed.). Los Angeles: Muthén \& Muthén.

Neuenhaus, N., Artelt, C., Lingel, K., \& Schneider, W. (2010). Fifth graders metacognitive knowledge: general or domain-specific? European Journal of Psychology of Education, 26, 163-178.

OECD. (2007). PISA 2006: Science competencies for tomorrows world-Analysis (Vol. I). Paris: OECD.

OECD. (2010). PISA 2009 Results: Learning to learn-Student engagement, strategies and practices (Vol. III). Paris: OECD.

Pappas, S., Ginsburg, H. P., \& Jiang, M. (2003). SES differences in young children's metacognition in the context of mathematical problem solving. Cognitive Development, 18, 431-450.

Paris, S. G., Lipson, M. Y., \& Wixson, K. K. (1983). Becoming a strategic reader. Contemporary Educational Psychology, 8, 293-316.

Paris, S. G., \& Paris, A. H. (2001). Classroom applications of research on self-regulated learning. Educational Psychologist, 36(2), 89-101.

Paris, S., \& Winograd, P. (1990). Promoting metacognition and motivation of exceptional children. Remedial and Special Education, 11(6), 7-15.

Pierce, S. H., \& Lange, G. (2000). Relationships among metamemory, motivation and memory performance in young school-age children. British Journal of Developmental Psychology, 18, 121-135.

Pintrich, P. R. (2002). The role of metacognitive knowledge in learning, teaching, and assessing. Theory into Practice, 41(4), 219-225.

Pintrich, P. R., \& DeGroot, E. V. (1990). Motivational and self-regulated learning components of classroom academic performance. Journal of Educational Psychology, 82(1), 33-40.

Pressley, M., Borkowski, J. G., \& Schneider, W. (1989). Good information processing: What it is and how education can promote it. International Journal of Educational Research, 13, 857-867.

Rheinberg, F., Vollmeyer, R., \& Rollett, W. (2005). Motivation and action in self-regulated learning. In M. Boekaerts, P. R. Pintrich, \& M. Zeidner (Eds.), Handbook on self-regulation. Directions and challenges for future research (pp. 503-529). San Diego, CA: Academic Press.

Roeschl-Heils, A., Schneider, W., \& van Kraayenoord, C. E. (2003). Reading, metacognition and motivation: A follow-up study of German students in Grades 7 and 8. European Journal of Psychology of Education, 18(1), 75-86. 
Schermelleh-Engel, K., Moosbrugger, H., \& Müller, H. (2003). Evaluating the fit of structural equation models: Tests of significance and descriptive goodness-of-fit measures. Methods of Psychological Research Online, 8(2), 23-74.

Schiefele, U., \& Wild, K. P. (2000). Interesse und Lernmotivation: Untersuchungen zu Entwicklung, Förderung und Wirkung [Interest and learning motivation: Studies on development, promotion, and effect]. Münster: Waxmann.

Schlagmüller, M., \& Schneider, W. (2007). Würzburger Lesestrategie - Wissenstest für die Klassen 7-12 (WLST 7-12). [Würzburger Reading Strategy Knowledge Test for Grades 7-12 (WLST 7-12)]. Göttingen: Hogrefe.

Schmitz, B. (2001). Self-Monitoring zur Unterstützung des Transfers einer Schulung für Selbstregulation für Studierende: Eine prozessanalytische Untersuchung [Self-monitoring to support transfer of training in self-regulation for students: A process-analytical study]. Zeitschrift für Pädagogische Psychologie, 15(3/4), 181-197.

Schneider, W. (2010). Metacognition and memory development in childhood and adolescence. In $H$. S. Waters \& W. Schneider (Eds.), Metacognition, strategy use, and instruction (pp. 54-81). New York: Guilford.

Schneider, W., \& Lockl, K. (2002). The development of metacognitive knowledge in children and adolescents. In B. L. Schwartz \& T. J. Perfect (Eds.), Applied metacognition (pp. 224-257). Cambridge: Cambridge University Press.

Schneider, W., \& Lockl, K. (2006). Entwicklung metacognitive Kompetenzen im Kindes und Jugendalter [Development of metacognitive competencies during childhood and adolescence]. In W. Schneider \& B. Sodian (Eds.), Kognitive Entwicklung [cognitive development] (pp. 721-767). Göttingen: Hogrefe.

Schraw, G. (1998). Promoting general metacognitive awareness. Instructional Science, 26(1-2), 113-125.

Schraw, G., Crippen, K. J., \& Hartley, K. (2006). Promoting self-regulation in science education: Metacognition as part of a broader perspective on learning. Research in Science Education, 36, 111-139.

Sperling, R. A., Howard, B. C., Staley, R., \& DuBois, N. (2004). Metacognition and self-regulated learning constructs. Educational Research and Evaluation: An International Journal on Theory and Practice, 10(2), 117-139.

Steyer, R., Eid, M., \& Schwenkmezger, P. (1997). Modeling true intraindividual change: True change as a latent variable. Methods of Psychological Research, 2, 21-33.

Thillmann, H. (2007). Selbstreguliertes Lernen durch Experimentieren: Von der Erfassung zur Förderung [Self-regulated learning through experimenting: From assessing to fostering]. (Doctoral dissertation, University of Duisburg-Essen). Download of the online publication of the dissertation at the University of Duisburg-Essen. http://duepublico.uni-duisburg-essen.de/servlets/DocumentServlet?id=17311. Accessed 09 Nov 2012.

Veenman, M. V. J., Van Hout-Wolters, B. H. A. M., \& Afflerbach, P. (2006). Metacognition and learning: Conceptual and methodological considerations. Metacognition and Learning, 1, 3-14.

Wolters, C. A. (1999). The relation between High School students' motivational regulation and their use of learning strategies, effort, and classroom performance. Learning and Individual Differences, 11, 281-299.

Yerdelen-Damar, S., \& Pesman, H. (2013). Relations of gender and socioeconomic status to physics through metacognition and self-efficacy. Journal of Educational Research, 106(4), 280-289. doi:10.1080/ 00220671.2012 .692729 .

Zohar, A. (2012). Explicit teaching of metastrategic knowledge: Definitions, students' learning, and teachers' professional development. In A. Zohar \& Y. J. Dori (Eds.), Metacognition in science education: Trends in current research, contemporary trends and issues in science education, 40, 197-223. doi:10.1007/978-94-007-2132-6_9.

Zohar, A., \& Peled, B. (2008). The effects of explicit teaching of metastrategic knowledge on low- and highachieving students. Learning and Instruction, 18, 337-353. 